\title{
Decompressive Craniotomy and Fast-Track Duraplasty in Acute Subdural Hematomas
}

\author{
Ehab El Refaee, Ahmed Elsayed, Ahmed El-Fiki, Hisham El Shitany \\ Department of Neurosurgery, Cairo University, Cairo, Egypt \\ Email: drahmed73@gmail.com
}

How to cite this paper: El Refaee, E., Elsayed, A., El-Fiki, A. and El Shitany, H. (2019) Decompressive Craniotomy and Fast-Track Duraplasty in Acute Subdural Hematomas. Open Journal of Modern Neurosurgery, 9, $35-42$.

https://doi.org/10.4236/ojmn.2019.91005

Received: November 5, 2018

Accepted: December 14, 2018

Published: December 17, 2018

Copyright $\odot 2019$ by authors and Scientific Research Publishing Inc. This work is licensed under the Creative Commons Attribution International License (CC BY 4.0).

http://creativecommons.org/licenses/by/4.0/

\begin{abstract}
Background: Traumatic subdural hematoma is one of the severe injuries to brain with high mortality rates. Dural opening is often associated with brain herniation against the dural edges due to associated edema that would lead to venous infarction. Aim: The objective of this study is to describe a technical note that would allow fast and effective closure of the dura after hematoma evacuation via duraplasty with analysis of the safety and competency of the technique. Subjects and Methods: The fast-track technique was implemented in 15 successive cases with acute subdural hematoma where the fascia lata flap was prepared and sutured to the planned dural incision before opening the dura, which allowed fast and effective closure of the dura before brain herniation. Subdural bridges were planned by using Gelfoam to prevent venous compression. Analysis of the technique effectiveness was performed by the operative detection of brain herniation, as well as clinical and radiological follow-up of patients. Results: All patients had a Glasgow coma score (GCS) below six before the operation. Mean time from trauma to surgery was five hours. The dura could be effectively closed with no brain herniation in all cases. Nine patients survived (60\%), where five of them ended up in a vegetative state. Of these two recovered and three continued in a persistent vegetative state. The mortality rate was $40 \%$. Post-operative infarction was detected in post-operative imaging of four patients. Conclusion: The fast-track duraplasty technique is fast and effective in prevention of brain herniation during surgery with favorable clinical outcome in comparison with the poor and severely deteriorated preoperative clinical presentation. More studies to evaluate the impact of the technique on the survival rate are warranted.
\end{abstract}

\section{Keywords}

Traumatic Subdural Hematoma, Decompressive Craniotomy, Duraplasty 


\section{Introduction}

Traumatic brain injury (TBI) can cause alteration in brain function due to the external force [1]. The treatment goal of severe TBI is to reduce and prevent intracranial hypertension (ICH). The pathologic increase in intracranial pressure (ICP) may compromise cerebral perfusion pressure (CPP) and lead to neurologic deficit and fatal brain herniation syndromes [2].

Medical and surgical treatment options are comprehensively discussed in literature. However, the acute subdural hematoma (SDH) occurs due to severe hemorrhage and would require a surgical decompression in many instances. The subdural hematoma is usually extensive, covering a large part of the hemisphere and sufficient access requires a standard trauma craniotomy [3]. There is still a debate about whether to perform a craniectomy or a decompressive craniotomy after evacuation of the hematoma.

However, there is no level I evidence demonstrating improvement in patient outcomes through definitive, surgical management of ICH [4]. In severe cases with extensive brain injury, the subdural hematoma is associated with severe brain edema which would hinder proper closure of the dura even with duraplasty in many instances, leaving opened dural edges which might cause more venous congestion if a vein is trapped against this opened dura. In this study, we developed a technique that helps to close the dura in a fast track method as soon as the hematoma is evacuated and before any brain herniation through the dura opening.

\section{Subjects and Methods}

This case series included 15 successive patients with severe brain injury associated with acute subdural hematomas that needed surgical evacuation during the period January-June 2017. The severity of the associated brain injury was considered when the Glasgow coma score was ranging from 4 to 6 on admission (Figure 1(a)). Otherwise, all patients were operated upon by decompressive craniotomy through evacuation of the hematoma with dural closure by Fast track duraplasty technique in Cairo University Hospitals. The cases with GCS less than 4 or associated with severe co-morbidities where excluded from this study. Complete physical and neurological examination was performed to the enrolled patients upon admission. After patient's stabilization, Initial imaging examinations were performed. Post-operative computed tomography (CT) imaging was obtained to all patients one week after surgery (Figure 1(b)) and six month later.

Surgical technique:

Elevation of the patients head 30 degrees was done. Hyperventilation and intravenous mannitol administration were performed in all patients before evacuation of the hematoma. After induction of anesthesia, the fascia harvested from Fascia lata was prepared and sutured to one edge of the planned dural incision before opening the dura, which allowed fast and effective closure of the dura before brain herniation. Opening the dura in a $c$ shaped incision along the 


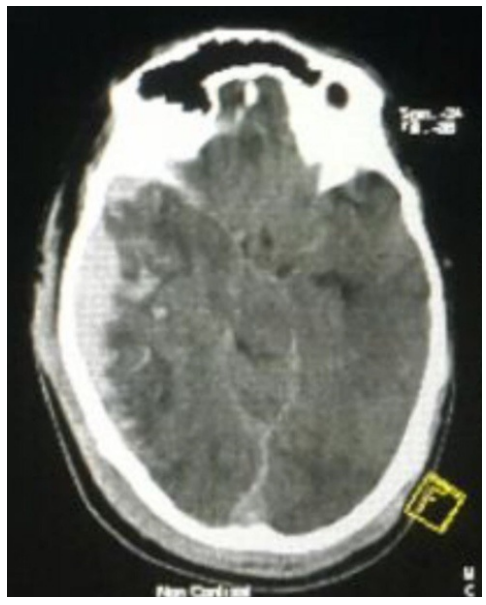

(a)

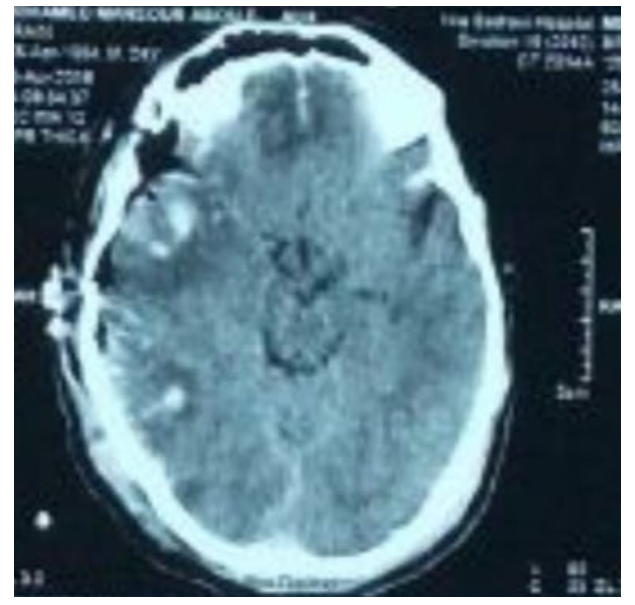

(b)

Figure 1. (a) Post traumatic CT brain axial cut showing a left temporal acute SDH with underlying brain contusion and obliterated basal cisterns; (b) Axial CT scan of the same case a week after surgery denoting decompression and regressive brain edema.

sutured fascia line was followed by sub-dural bridges around the big veins by using Gelatin sponge to prevent venous compression, then suturing the remaining limb of the along the remaining limb of the opened dural edge (Figure 2). After duraplasty, the bone flap was left flail to allow adequate decompression (Figure 3).

\section{Evaluation:}

Analysis of the brain herniation during surgery was mentioned in the operative details written by the neurosurgeon together with the effectiveness of dural closure with this technique. Clinical and radiological outcome was evaluated immediately after operation and at six months follow up.

\section{Results}

Fifteen cases were studied including three females and twelve males; the mean age was 36.8 ranging from 10 to 75 years old. They all had severe traumatic brain injury resulted in acute subdural hematomas and brain compression. The hematoma was left sided in ten cases and right sided in five cases. Evacuation of the hematoma and dural closure by Fast track were performed to all patients included in this study. Patient data are shown in Table 1.

The best outcome was related directly to the severity of trauma, age and the level of consciousness upon admission. In reference to the patients' data (Table 1 ), the regained consciousness was observed in cases with initial GCS not less than 6 and in young age (less than 38 years).

Upon the use of this technique, no single event of intractable brain herniation was encountered intraoperatively. The dural flap could be fully sutured in all cases.

Follow up:

The study included 15 successive cases with severe head trauma either due to 
Table 1. Patient's data.

\begin{tabular}{|c|c|c|c|c|c|c|c|}
\hline No & Age & Gender & Site of hemorrhage & Mode of trauma & GCS on admission & $\begin{array}{l}\text { Post-operative imaging } \\
\text { one week after surgery }\end{array}$ & $\begin{array}{l}\text { Clinical outcome } \\
\text { after } 6 \text { months }\end{array}$ \\
\hline 1 & 36 & M & $\mathrm{L}$ & Car accident & 5 & minimal hypodensity & Persistent vegetative state \\
\hline 2 & 65 & M & $\mathrm{R}$ & Car accident & 5 & $\begin{array}{l}\text { no infarction, } \\
\text { small contusion }\end{array}$ & $\begin{array}{c}\text { Died } \\
\text { (one week after surgery) }\end{array}$ \\
\hline 3 & 24 & M & $\mathrm{L}$ & Direct head trauma & 6 & $\begin{array}{l}\text { no infarction, minimal } \\
\text { residual subdural } \\
\text { hemorrhage }\end{array}$ & $\begin{array}{c}\text { Persistent } \\
\text { vegetative state }\end{array}$ \\
\hline 4 & 21 & $\mathrm{~F}$ & $\mathrm{R}$ & car accident & 6 & $\begin{array}{l}\text { minimal contralateral } \\
\text { subdural hemorrhage }\end{array}$ & $\begin{array}{l}\text { regained consciousness, } \\
\text { no deficit }\end{array}$ \\
\hline 5 & 60 & M & $\mathrm{L}$ & Direct head trauma & 4 & frontal infarction & $\begin{array}{c}\text { Died } \\
\text { (9 days postoperatively) }\end{array}$ \\
\hline 6 & 18 & M & $\mathrm{L}$ & Car accident & 6 & $\begin{array}{l}\text { No infarction } \\
\text { or hypodensity }\end{array}$ & $\begin{array}{l}\text { Regained Consciousness, } \\
\text { no deficit, wound } \\
\text { infection managed } \\
\text { conservatively }\end{array}$ \\
\hline 7 & 24 & M & $\mathrm{L}$ & fall from height & 6 & $\begin{array}{l}\text { Frontal infarction, } \\
\text { small contusions }\end{array}$ & $\begin{array}{l}\text { regained consciousness } \\
\text { after being } \\
\text { in vegetative state }\end{array}$ \\
\hline 8 & 65 & M & $\mathrm{L}$ & Car accident & 5 & $\begin{array}{l}\text { No infarction } \\
\text { or hypodensity }\end{array}$ & $\begin{array}{c}\text { persistent } \\
\text { Vegetative state }\end{array}$ \\
\hline 9 & 15 & M & $\mathrm{R}$ & Car accident & 6 & $\begin{array}{l}\text { Fronto-temporal } \\
\text { hypodensity }\end{array}$ & $\begin{array}{l}\text { regained consciousness, } \\
\text { no deficit }\end{array}$ \\
\hline 10 & 10 & M & $\mathrm{L}$ & Car accident & 4 & $\begin{array}{l}\text { Hemispherical infarction, } \\
\text { brain stem infarction }\end{array}$ & $\begin{array}{c}\text { Died } \\
\text { (10 days postoperatively) }\end{array}$ \\
\hline 11 & 38 & $\mathrm{~F}$ & $\mathrm{~L}$ & Car accident & 6 & $\begin{array}{l}\text { No infarction } \\
\text { or hypodensity }\end{array}$ & $\begin{array}{l}\text { regained consciousness, } \\
\text { no deficit }\end{array}$ \\
\hline 12 & 54 & $\mathrm{~F}$ & $\mathrm{R}$ & fall from height & 5 & frontal infarction & $\begin{array}{l}\text { Died (12 days } \\
\text { postoperatively) }\end{array}$ \\
\hline 13 & 67 & M & $\mathrm{L}$ & car accident & 6 & Fronto-temporal infarction & $\begin{array}{c}\text { Died ( } 8 \text { days } \\
\text { postoperatively) }\end{array}$ \\
\hline 14 & 75 & M & $\mathrm{L}$ & Car accident & 5 & couldn't be obtained & $\begin{array}{c}\text { Died (3 days } \\
\text { post operatively) }\end{array}$ \\
\hline 15 & 35 & M & $\mathrm{R}$ & Fall from height & 6 & $\begin{array}{l}\text { No infarction } \\
\text { or hypodensity }\end{array}$ & $\begin{array}{l}\text { regained consciousness } \\
\text { after being in } \\
\text { vegetative state }\end{array}$ \\
\hline
\end{tabular}

fall from height, car accidents or isolated head trauma. The mean follow up period was 6 months. Among the cases enrolled in the study, 9 (60\%) cases regained consciousness but three patients ended up in a persistent vegetative state at the end follow up. Post-operative infarction was encountered in 4 (26.6\%) cases while minimal hypodensities/hemorrhage were reported in $5(33.3 \%)$ cases. One case experienced minimal contralateral subdural hematoma.

Six cases died ( 4 of them over 60 year's age) either due to severity of trauma, or due to other causes. Wound infection was reported in one case postoperatively and was managed conservatively. 


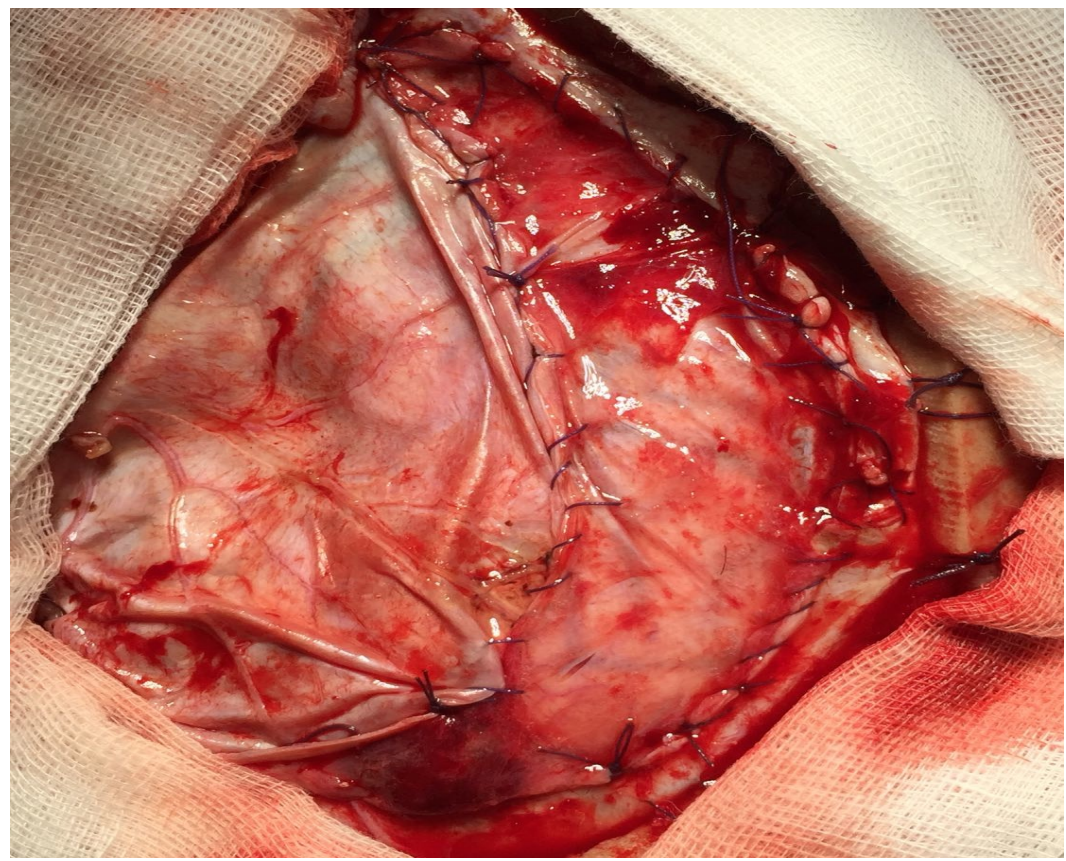

Figure 2. Intraoperative image showing the fast track duraplasty where the graft was sutured to the planned dural incision before opening the dura.

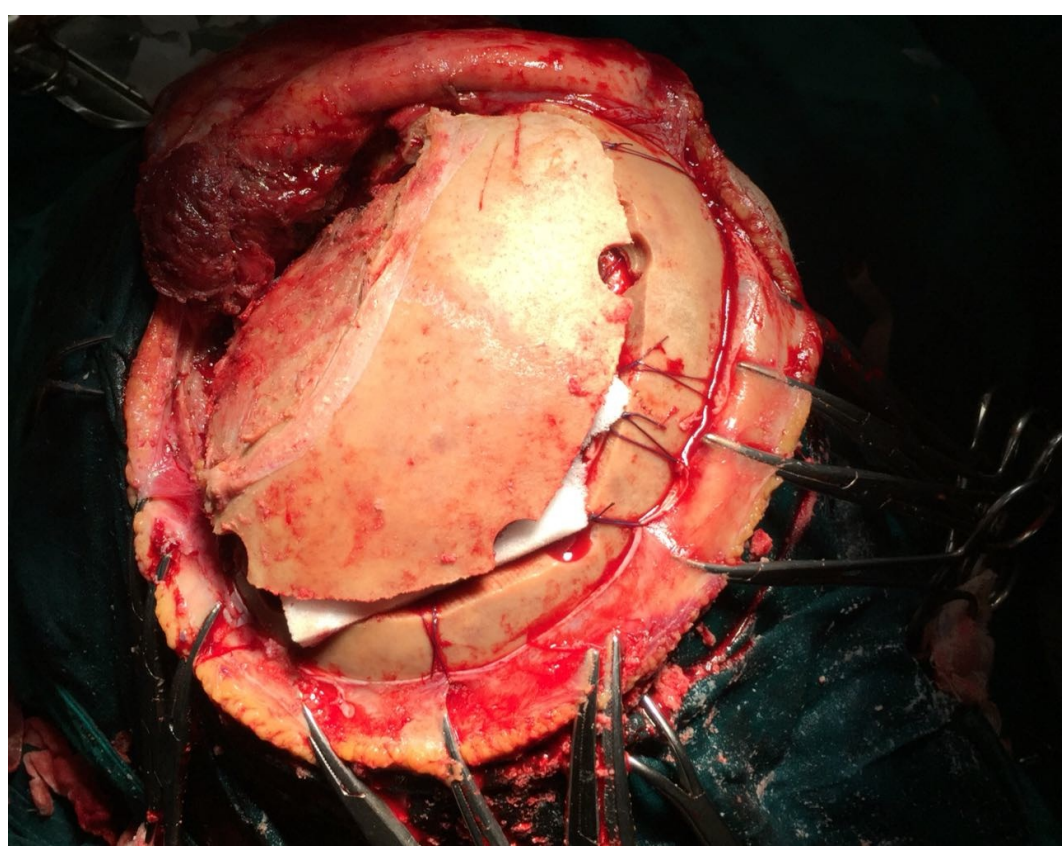

Figure 3. After duraplasty, the bone flap was left flail to allow adequate decompression.

\section{Discussion}

Traumatic brain injury is one of the most common presentations in the neurosurgery emergency department. In the United States, 1.6 million individuals are affected annually. Some have estimated the mortality rates for the elderly with a $\mathrm{SDH}$ that require neurosurgical intervention to be as high as 90\% [5] [6] [7] [8]. The outcome is directly related to the severity of trauma, level of consciousness 
as well as age of the patient, where the worst outcome found in elderly patients [9] [10] [11].

Increasing age is a strong independent factor in prognosis of severe TBI, with a significant increase in poor outcome in patients older than 60 years of age [10]. However, in previous studies, with the use of all assistant tools to monitor and control the ICP, the better prognosis was more attributed to the initial level of consciousness rather than the age of the patient where patients with GCS better than 8 experienced a good recovery after surgery in most of the cases [11].

There is still not enough evidence demonstrating improvement in patient outcomes through definitive, surgical management of intracranial hemorrhage [4] [12]. The idea of wide decompressive craniectomy in massive traumatic brain swelling is based on the principle of Monro-Kellie Doctrine that tells 'total intracranial volume is fixed because of rigid and inelastic nature of skull which contains brain [13].

Intractable intraoperative brain herniation can occur due to several pathologies [14]. The brain would rather herniate through the craniotomy if adequate duraplasty was not affordable. This made many neurosurgical institutes prefer decompressing the angry brain via multiple dural stabs [15]. However, the outcome depends upon the ability to control the intracranial pressure rather than removal of the hematoma, so that we established a fast track technique to suture the flap to one edge of the planned dural incision, in order to afford the opportunity to quickly suture the dural flap to the remaining dural edges via running sutures before the herniation of the brain from the dural edges. Subdural bridges via Gelatin Sponge were also performed to avoid kinking of the large cortical veins against the dural edges. This technique is regularly used nowadays in our institute and it prevented any intraoperative event of intractable brain herniation and with favorable outcome.

Some limitations were associated with the current study. They included the small numbers of cases and the severe brain injury state that was associated with other injuries reported in cases included in the study on admission time which was reflected on GCS (ranging from 4 to 6). Those limitations contributed in the functional outcome achieved by the current study. Moreover, the study provided an effective new technique that needs further studies to indicate its efficacy.

Previous studies mentioned the decompressive craniectomy, or craniotomy that can be associated with implantation of the bone flap in the patient's' abdomen, as effective in the management of acute subdural hematomas [16] [17]. In comparison to the recent techniques of decompression, the temporalis hinged craniotomy is considered cost effective with excellent results [18].

\section{Conclusion}

The fast track duraplasty technique is fast and effective in prevention of brain herniation during surgery with favorable clinical outcome in comparison with the poor and severely deteriorated preoperative clinical presentation. More studies to evaluate the impact of the technique on the survival rate are warranted. 


\section{Conflicts of Interest}

The authors declare no conflicts of interest regarding the publication of this paper.

\section{References}

[1] Website. National Institute of Neurological Disorders and Stroke. NINDS Common Data Elements: Traumatic Brain Injury. https://www.commondataelements.ninds.nih.gov/TBI.aspx\#tab=Data_Standards

[2] Stocchetti, N. and Maas, A.I.R. (2014) Traumatic Intracranial Hypertension. The New England Journal of Medicine, 370, 2121-2130. https://doi.org/10.1056/NEJMra1208708

[3] Jiang, J.-Y., Xu, W., Li, W.-P., et al. (2005) Efficacy of Standard Trauma Craniectomy for Refractory Intracranial Hypertension with Severe Traumatic Brain Injury: A Multicenter, Prospective, Randomized Controlled Study. Journal of Neurotrauma, 22, 623-628. https://doi.org/10.1089/neu.2005.22.623

[4] Bullock, M.R., Ross Bullock, M., Chesnut, R., et al. (2006) Surgical Management of Acute Subdural Hematomas. Neurosurgery, 58, S2-S16-S2-S24.

[5] Cooper, P.R., Rovit, R.L. and Ransohoff, J. (1976) Hemicraniectomy in the Treatment of Acute Subdural Hematoma: A Re-Appraisal. Surgical Neurology, 5, 25-28.

[6] Cagetti, B., Cossu, M., Pau, A., Rivano, C. and Viale, G. (1992) The Outcome from Acute Subdural and Epidural Intracranial Haematomas in Very Elderly Patients. British Journal of Neurosurgery, 6, 227-231. https://doi.org/10.3109/02688699209002930

[7] Jamjoom, A. (1992) Justification for Evacuating Acute Subdural Haematomas in Patients above the Age of 75 Years. Injury, 23, 518-520.

https://doi.org/10.1016/0020-1383(92)90149-M

[8] Jones, N.R., Blumbergs, P.C. and North, J.B. (1986) Acute Subdural Haematomas: Aetiology, Pathology and Outcome. ANZ Journal of Surgery, 56, 907-913. https://doi.org/10.1111/j.1445-2197.1986.tb01853.x

[9] Celso, B., Tepas, J., Langland-Orban, B., et al. (2006) A Systematic Review and Meta-Analysis Comparing Outcome of Severely Injured Patients Treated in Trauma Centers Following the Establishment of Trauma Systems. Journal of Trauma, 60, 371-378.

[10] Taussky, P., Hidalgo, E.T., Landolt, H. and Fandino, J. (2012) Age and Salvage Ability: Analysis of Outcome of Patients Older than 65 Years Undergoing Craniotomy for Acute Traumatic Subdural Hematoma. World Neurosurgery, 78, 306-311.

[11] El-Fiki, M. (2012) Acute Traumatic Subdural Hematoma Outcome in Patients Older than 65 Years. World Neurosurgery, 78, 228-230.

[12] Bullock, M.R., Ross Bullock, M., Chesnut, R., et al. (2006) Surgical Management of Traumatic Parenchymal Lesions. Neurosurgery, 58, S2-S25-S2-S46.

[13] Kellie, G. (1824) Reflections on the Pathology of the Brain: Part II. Trans Med Chir Soc Edinb, 1, 123-169.

[14] Foo, L.L., Chaw, S.H., Chan, L., Ganesan, D. and Karuppiah, R. (2017) Intractable Intraoperative Brain Herniation Secondary to Tension Pneumocephalus: A Rare Life-Threatening Complication during Drainage of Subdural Empyema. Brazilian Journal of Anesthesiology, 67, 655-658. https://doi.org/10.1016/j.bjan.2015.09.006

[15] Bhat, A.R., Kirmani, A.R. and Wani, M.A. (2013) Decompressive Craniectomy with 
Multi-Dural Stabs-A Combined (SKIMS) Technique to Evacuate Acute Subdural Hematoma with Underlying Severe Traumatic Brain Edema. Asian Journal of Neurosurgery, 8, 15-20. https://doi.org/10.4103/1793-5482.110275

[16] Elshanawany, A.M. and Essa, A.A. (2018) Traumatic Acute Subdural Hematoma: Treatment by Evacuation with Decompressive Craniotomy and Cranioplasty, Case Series and Surgical Outcome Analysis. OJMN, 8, 331-341.

https://doi.org/10.4236/ojmn.2018.83028

[17] Kwon, Y.S., Yang, K.H. and Lee, Y.H. (2016) Craniotomy or Decompressive Craniectomy for Acute Subdural Hematomas: Surgical Selection and Clinical Outcome. Korean Journal of Neurotrauma, 12, 22. https://doi.org/10.13004/kjnt.2016.12.1.22

[18] Adeleye, A.O. and Azeez, A.L. (2011) Decompressive Craniectomy Bone Flap Hinged on the Temporalis Muscle: A New Inexpensive Use for an Old Neurosurgical Technique. Surgical Neurology International, 2, 150.

https://doi.org/10.4103/2152-7806.86227 